\title{
Etnografía de los procesos alimentarios y el poder en regiones indígenas de Chiapas
}

\section{Ethnography of Eating Habits and Power in Indigenous Regions of Chiapas}

\author{
Marina Alonso Bolaños \\ JAVIER GuTIÉrRez SÁNCHEZ \\ Instituto Nacional de Antropología e Historia, México \\ Fermín Ledesma Domínguez \\ Universidad Autónoma Metropolitana, Unidad Xochimilco, México \\ Rosalba Tadeo Castro \\ Instituto Nacional de Antropología e Historia, México
}

\begin{abstract}
RESUmEn: El objetivo de este artículo es aportar elementos al conocimiento etnográfico de los procesos alimentarios en distintas regiones tsotsiles, tseltales, zoques y ch'oles de Chiapas en el contexto de la diversidad cultural y las relaciones de poder. Se demuestra que la comida, en tanto hecho social dinámico, es un campo observable en el cual se expresan distintas escalas y niveles del poder social y político entre el Estado, el sistema de mercado, la sociedad nacional y los pueblos indígenas, como al interior de estos últimos en ámbitos regionales y locales específicos. Se plantea la categoría antropológica de "control" para explicar lo alimentario en lo que concierne a la esfera de la experiencia social de la elaboración de la comida y su consumo.
\end{abstract}

Palabras clave: Chiapas; procesos alimentarios; relaciones de poder; comida; control social.

Aвstract: The objective of this article is to contribute to the ethnographic knowledge of eating habits in Tsotsil, Tseltal, Zoque and Ch'ol regions of Chiapas in the context of cultural diversity and power relationships. It shows that food as a dynamic social fact is a research field in which different scales and levels of social and political power are expressed. Likewise, inequalities between State, market system, national society and Indigenous people are manifested in the eating habits, as well 
as among particular regional and local contexts. The anthropological category of "control" is proposed in order to explain the relations between social experience of production and consumption of food.

KeYwords: Chiapas; eating habits; power relationships; food; social control.

ReCEPCIÓN: 14 de mayo de 2019.

ACEPTACIÓN: 20 de septiembre de 2019.

Dor: https://doi.org/10.19130/iifl.ecm.2020.56.2.0010

\section{Introducción}

La práctica alimentaria cruza de forma transversal y dinámica las esferas de la vida colectiva (Arnáiz, 2008) y por esta razón el acto de comer constituye un "hecho social total", haciendo referencia al concepto que Mauss estableció para indicar el entramado indisolube de instituciones que configuran la realidad social (1979: 272-273); de manera que se podría observar dicho fenómeno como parte del intercambio y la reciprocidad entre los miembros de un grupo y reparar en que la comida "participa en la esencia profunda de los individuos y refleja las características íntimas del ethos cultural” (Arnáiz, 2008: 11). Asimismo, el acto alimentario como hecho social total puede ser pensado como un valor o visto como un acto de poder, lo cual permite entrever también su sentido político (Carrasco, 2007: 84). Más allá de que la alimentación sea un eje de la vida social de los pueblos indígenas, constituye un campo priviegiado para observar las relaciones de poder entre el Estado, la sociedad nacional y los pueblos indígenas, trátese de ámbitos regionales o bien locales. De hecho, es en la práctica alimentaria que distintos niveles y grupos de poder definen el acceso o "apropiación diferenciada" (Reygadas, 2004: 10) de los alimentos y determinan, en cierta medida, los gustos y preferencias por ciertas comidas sobre otras estigmatizando aquellas que consumen otros sectores de su sociedad o bien rechazando las prácticas alimentarias de sus alteridades étnicas.

Huelga decir que desde hace un par de décadas la literatura en torno a la comida y los distintos procesos asociados a ella es abundante; en particular, el interés por el tema se ha centrado en las tesis sobre la seguridad y soberanía alimentaria, así como el cambio social visto a través del estudio de los patrones o hábitos de nutrición y el menú dietético de las poblaciones. Sin embargo, en este artículo nos proponemos aportar elementos al conocimiento y reflexión etnográficos de los procesos alimentarios, la diversidad de prácticas y hábitos alimentarios en el contexto de las relaciones de poder. Para dar cuenta de ello, hemos planteado "el control" de lo que se come como una categoría antropológica que permita explicar la experiencia social de la elaboración de la comida, que en muchos casos incluye su producción cuando se trata de grupos campesinos 
y su consumo. Esto posibilita observar la manera en que se articulan los grupos sociales y sus espacios, así como la idea que tienen los sujetos acerca de que la comida determina la salud, la enfermedad y configura el cuerpo de los individuos.

El presente artículo es producto del proyecto de investigación "Diversidad cultural, discriminación y racismo en el México indígena" desarrollado entre 2015 y 2017 en el marco del Programa Nacional de Etnografía de las Regiones Indígenas llevado a cabo por el Instituto Nacional de Antropología e Historia desde hace dos décadas. De ahí que echemos mano de la etnografía obtenida en estudios anteriores a esa fecha. La etnografía, por tanto, refleja una temporalidad y espacialidad amplia para una reflexión transversal etnológica en localidades de las regiones: zoques de la depresión central y las estribaciones del volcán El Chichonal, tseltales y tsotsiles de Los Altos, ch'oles del norte y ch'oles, tzeltales y zoques de la selva lacandona, así como mames, mochós y cackchiqueles de la Sierra Madre (Figura 1). De esta manera, los datos de corte cualitativo son de gran alcance pues la etnografía refleja, de manera extensiva, aspectos observados por el equipo de investigación en distintas localidades, lo cual posibilita la comprensión de grandes procesos concernientes a lo alimentario.

En términos generales, la etnografía se desarrolló en estancias de investigación para la realización de observaciones y entrevistas a diversos sujetos, entre ellos, padres y madres de familia, jóvenes agricultores y campesinos, y autoridades locales. En tanto que hicimos uso de diferentes formas de participación propias de dicha metodología visitamos los comedores comunitarios en cada una de las localidades de estudio en la selva y la depresión central, y entrevistamos a personas que estuvieron directamente involucradas en la operación de programas públicos en materia de alimentación.

\section{Procesos, prácticas y hábitos alimentarios}

“Aquí en Ocotepec comemos así con el fin de ahu-
yentar el hambre y la necesidad”.
Ángel MoralES, Ocotepec, 2012

Es un hecho que los hábitos alimentarios de las poblaciones indígenas de Chiapas cambiaron a partir de los años setenta y ochenta del siglo xx debido al proyecto neoliberal y los sistemas de mercado. Así, en los últimos años la academia se ha abocado a desentrañar las vicisitudes del desarrollo neoliberal en lo que atañe a los patrones de alimentación porque en las sociedades modernas la alimentación está supeditada a la práctica que prioriza la rapidez y la corta duración como parámetros que regulan una mayor producción en el menor tiempo posible. Sin embargo, en la mayoría de las investigaciones ha imperado el análisis de las lógicas del capitalismo y sus discursos para enmarcar los mercados, el manejo del tiempo para la rentabilidad de la tierra y la producción de alimentos, la formulación de 

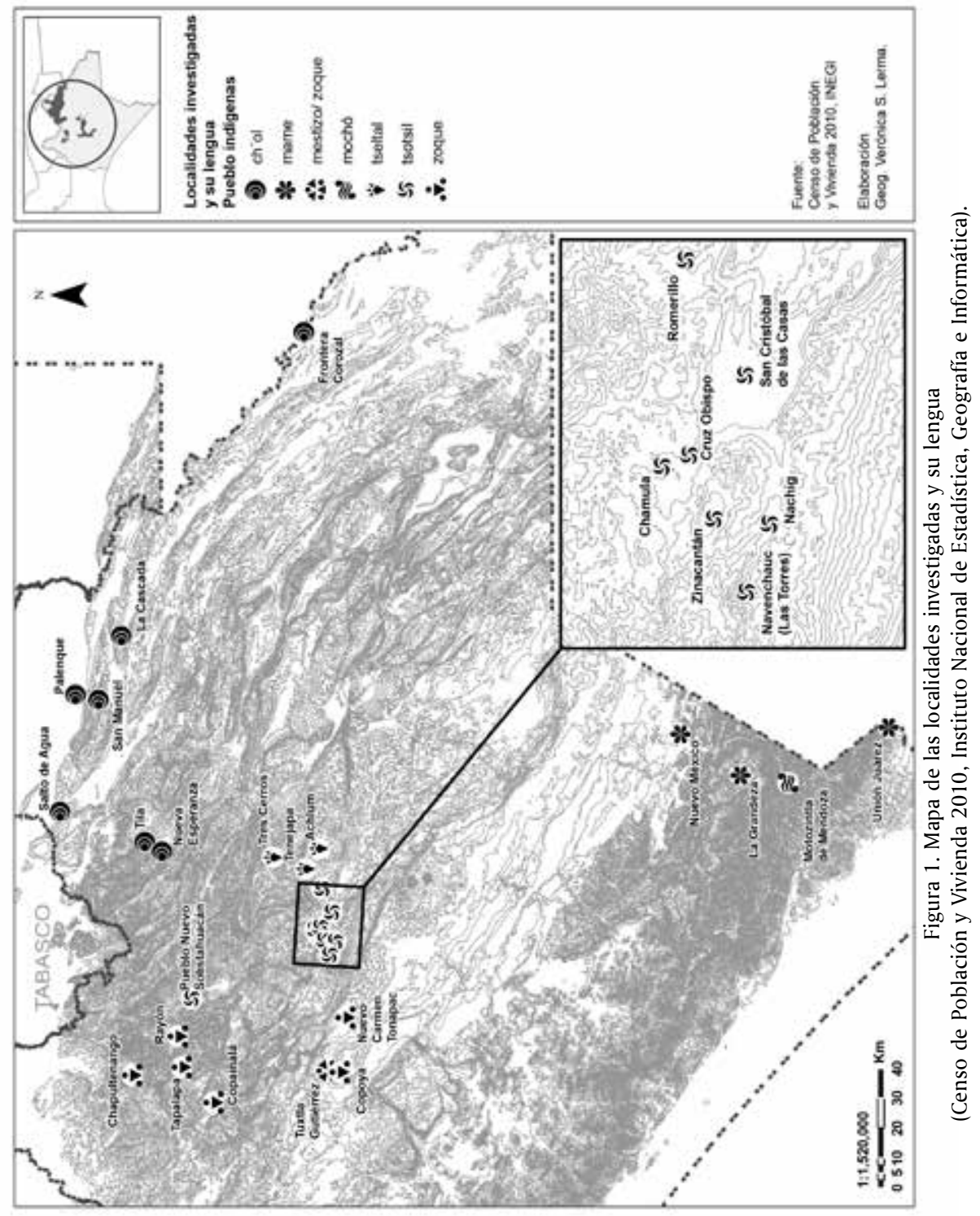
regiones productivas y su contraste con el impacto y las respuestas locales. El talante de dichas interpretaciones ha sido la contraposición de lo global con lo local siendo que, de acuerdo con Ayora (2002: 19), las comunidades no pueden entenderse ya en su sentido clásico como cerradas, estáticas "[...] y contrastantes con la sociedad 'moderna'. Por el contrario, son fluidas, inestables y cambiantes dentro una lógica no lineal” (Ayora, Vargas y Fernández, 2016: 45).

Debido a lo anterior, lejos de considerar la diversidad como resultado de lo distinto, debemos preguntarnos acerca de las desigualdades. Por un lado, tenemos lo relacionado con "lo indígena" por contraste con "lo no indígena" y, por el otro, la dimensión de "lo rural" ante "lo urbano"; veremos a continuación que las relaciones de poder son relativas pues dependen de los contextos en los cuales se enuncian. Para hacerlo comprensible, nos referiremos a la preocupación por la calidad de los alimentos, así como por su potencial peligrosidad en los términos en que los propios actores sociales lo han determinado.

Ello tiene que ver con la noción a partir de la cual los programas gubernamentales en pro de la alimentación del gobierno del entonces presidente Enrique Peña Nieto partieron del imaginario construido durante décadas en torno a lo indígena, explicaciones que también fueron esgrimidas en el campo educativo. Dichos argumentos partían de que las poblaciones indígenas eran ignorantes, antihigiénicas y que su alimentación diaria estaba desbalanceada. Estamos ante la configuración de una identidad estigmatizada (Goffman, 2006) que históricamente ha ubicado a los indígenas en una posición subordinada, a la cual se suma una condición de vulnerabilidad debido a la pobreza y marginación. La política pública alimentaria tuvo como propósito impulsar lo que se concebía como seguridad alimentaria de las poblaciones rurales, pero mediante el consumo de alimentos procesados por las agroindustrias, a la vez que restringió, mediante reglas aparentemente comunitarias, el consumo de alimentos cultural y localmente construidos, generando tensiones en la producción, las formas de circulación y de consumo. No obstante, la población indígena ha sostenido, hasta donde le es posible, ciertas formas que visualiza como tradicionales o propias: el hecho de que la alimentación y su forma de preparación, almacenaje, periodo de consumo, cantidad y calidad esté relacionada con los valores de lo frío y lo caliente, entre otros aspectos estrechamente vinculados con el parentesco, la pertenencia, intercambios, negociaciones y representaciones sociales como componentes que dan sentido de identidad local o regional.

Debemos resaltar que los procesos alimentarios, es decir, la comida en su más amplia acepción, constituyen un ámbito donde se despliega todo tipo de relaciones sociales. Por principio, la communitas —en términos de Turner (1988: 103) — organizada en distintos niveles y escalas muestra este espacio de la vida común. Aunque la población indígena migrante o habitante de las ciudades haya modificado sus formas de alimentación en lo que respecta a los productos a los cuales se tiene acceso, las formas de consumo buscan reproducir patrones culturales, hábitos tales como compartir los horarios con la familia e incluso la 
búsqueda de alimentos que satisfagan una suerte de estómago familiar; de hecho, según Mintz, "nada define más dramáticamente nuestra naturaleza de seres vivos que nuestra ingestión" (2003: 25), por tanto, la comida es una fuente de sociabilidad. En los planteamientos de la población de las zonas de investigación se hace hincapié en que la diferencia radica en los contextos urbanos donde se ha perdido la importancia de la preparación y compartición de alimentos (Figura 2).

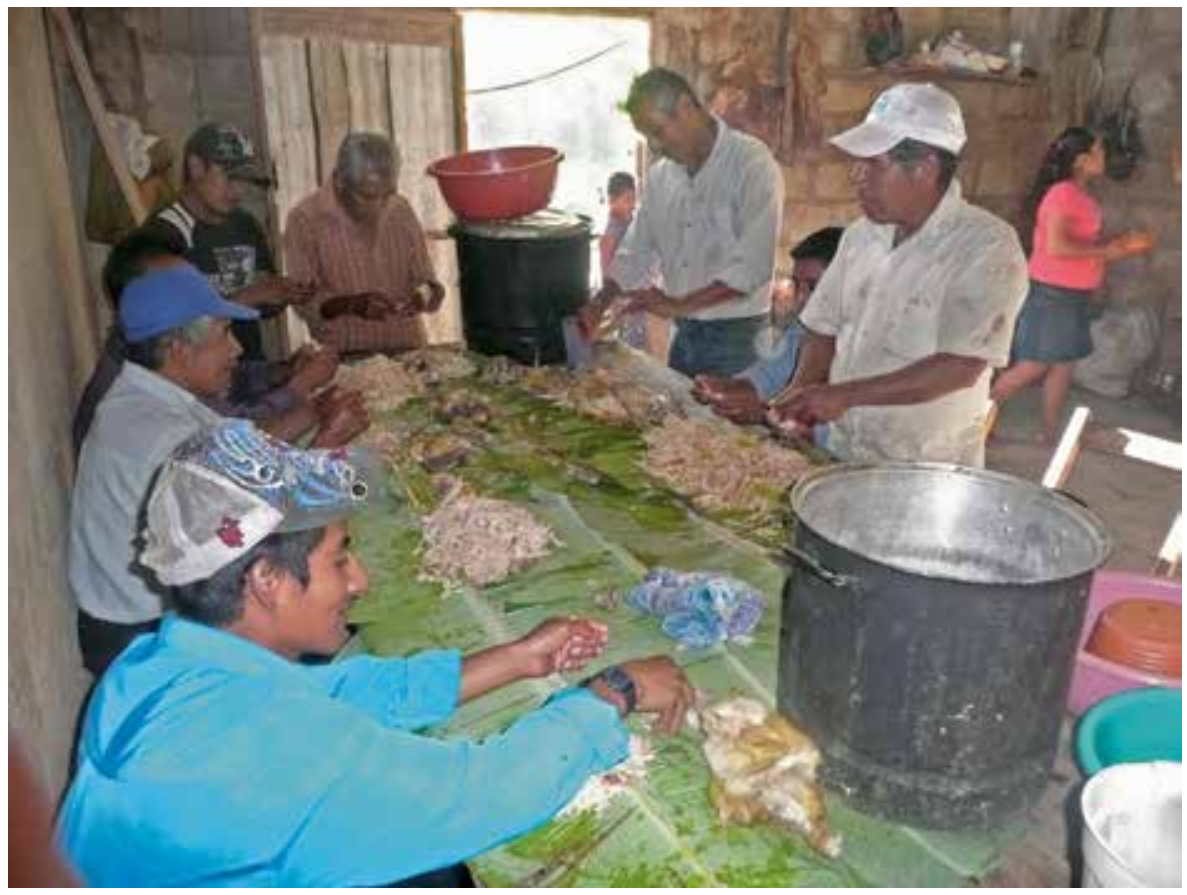

Figura 2. Hombres ch'oles preparando tamales para fiesta, Nueva Esperanza, Tila, 2012 (Fotografía de Javier Gutiérrez).

Lo anterior es importante si reparamos en que la ciudad no se opone a lo rural sino a la construcción de otras colectividades (Delgado, 1999: 23-24), de manera que la alimentación que se considera más indígena tendrá sobre sí misma el peso de distintos imaginarios. Por ejemplo, el hecho de que se trate de procesos y hábitos alimentarios de carácter colectivo hace que la interacción cotidiana cara a cara sea deseable, no obstante que la comida en sí misma no sea propiamente indígena. También debemos indicar la existencia de prohibiciones dietéticas en el mundo indígena, principalmente en el ámbito ritual en el cual se busca compartir y consumir lo considerado como propio que no proviene de la ciudad. Lo proscrito toca alimentos y bebidas que no deben ingerirse porque son de manufactura externa so pena de violentar la eficacia ritual, pero sobre todo las prohibiciones se refieren a las maneras de comer, por ejemplo, con el uso de cubiertos de mesa. 
Ahora bien, de acuerdo con la percepción de organizaciones de mujeres en la selva, el acceso diferenciado a los alimentos por parte de los sujetos determina la distinción entre lo urbano y lo rural debido a que los programas públicos en materia de alimentación del sexenio pasado ("La Cruzada Nacional contra el hambre" y "Canasta alimentaria del corazón") fueron instrumentadas en las poblaciones indígenas basándose en su condición rural o urbana. Asimismo, la educación pública ha influido en los procesos alimentarios en distintos momentos y niveles; en investigaciones anteriores hemos mostrado cómo jóvenes indígenas construían de formas particulares su relación con la tierra y sus productos como base de la alimentación, justo a partir de la educación que recibían en las escuelas y universidades (Alonso et al., 2015).

Varios casos remiten a esto, por ejemplo, el de una joven universitaria tseltal de Oxchuc quien siendo niña aprendió en la escuela que la tierra era un recurso natural explotable, idea que contrastaba con la forma en que su familia establecía vínculos con la milpa. Una vez que ingresó a la carrera se percató de la importancia del suelo y del agua, así como de los beneficios de un manejo adecuado a través de la producción local de alimentos, el uso medicinal de plantas y el reciclaje de desechos, de forma tal que revaloró los conocimientos de sus padres y dejó de considerar a la tierra como un recurso, sino como un entorno, un ambiente en el cual se habita. De igual manera, el deterioro ambiental ha figurado en el imaginario de sectores juveniles zoques, tsotsiles y mestizos de la Selva Negra ${ }^{1}$ como un episodio de crisis que definirá su futuro si no actúan para revertirlo y si no se ocupan en fortalecer las cocinas y formas locales de alimentarse que se encuentran en proceso de desplazamiento por las comidas rápidas e industrializadas.

Muchos jóvenes indígenas de Los Altos que en ese entonces entrevistamos decidieron migrar a las ciudades debido a que sus entornos habían sido prácticamente destruidos por el uso inadecuado o el abuso de sustancias para fertilizar, y debido a la escasez y empobrecimiento de los suelos pese a que las familias diversificaban sus formas de subsistencia. Por ejemplo, para las familias ch'oles el principal medio de subsistencia era la producción de hortalizas, pero a pesar de tener conciencia del cuidado ambiental, recurían al uso de fertilizantes y plaguicidas químicos para obtener frutos más vistosos y en menor tiempo. Los jóvenes sabían que estos artículos eran nocivos para el ambiente y la salud, pero a pesar de que lo explicaban a sus padres, éstos continuaron utilizándolos. Algo similar observamos que ocurría en Chamula, donde los agricultores aplicaban constantemente fertilizantes no obstante que las familias eran conscientes de la necesidad de dar descanso a sus parcelas, por lo cual, en ciertas temporadas del ciclo agríciola, rentaban tierras de labrar en Cruz Obispo, Ventana, Bechijtik y Kuch Lumtik. Además de estas parcelas y de sus propias milpas, la mayoría de las familias consumía alimentos que provenían de sus traspatios, espacios sobre los

\footnotetext{
${ }^{1}$ Nombre con el que se conoce a la región que cubre el bosque de niebla en los municipios de Rayón y una fracción de Pueblo Nuevo Solistahuacán.
} 
cuales tenían control. Lo anterior es interesante porque en las ciudades de origen zoque en la depresión central los habitantes han procurado instalar huertos urbanos para cultivar productos como el chipilín (Crotalaria longirostrata), cuyo uso es recurrente en la elaboración de platillos tradicionales.

\section{El control}

Es sabido que el denominado sistema global alimentario ha establecido procesos de homogenización de regímenes alimentarios ante los cuales existen complejos comportamientos de las poblaciones indígenas de Chiapas. McMichael (2015: 232) define el régimen alimentario como la "estructuración político-económica de la producción y el comercio internacional de alimentos, que proveen alimentos con dietas diferenciadas según las clases sociales, a través de distintas formas de poder hegemónico en la historia contemporánea". Empero, para no caer en simplificaciones casuísticas y ante el mapa analítico existente en torno a la alimentación, en este artículo referimos aquellos procesos alimentarios cuya premisa radica en el control de la alimentación.

Planteamos la noción de "control de lo que se come" como categoría antropológica para explicar lo alimentario en relación con la esfera de la experiencia social de la producción, la distribución y el consumo de alimentos que generan, y a su vez son generados por relaciones asimétricas. Se trata de respuestas locales de los sujetos y sus agentividades en permanente tensión. El control implica la capacidad de elegir y decidir lo que se come, se produce y la forma en que se distribuye; también incluye la creencia por parte de los sujetos en la superioridad de unos y la inferioridad de otros a partir del fenómeno de la alimentación y su acceso, de ahí que el control integre la inclusión y se relacione con su contraparte la exclusión.

De acuerdo con Harris (2011: 13) el inventario dietético de la mayoría de los grupos humanos parece ser bastante reducido de cara a la gama de posibles alimentos en el mundo, aspecto que responde a la cultura dietética de cada sociedad. No obstante este peso cultural y frente a la aseveración de Lévi-Strauss con respecto a que se alimenta la mente colectiva antes de alimentar el estómago, Harris no duda en indicar que se alimenta el estómago colectivo antes de alimentar la mente, ya que los alimentos preferidos son "aquellos que presentan una relación de costes y beneficios más favorables que los alimentos que se evitan" (Harris, 2011: 16-17); no obsta decir que existen alimentos sumamente nutritivos pero cuyo costo en producción es elevado y por ello en ocasiones son evitados.

Si bien la afirmación anterior pudiera parecer un tanto determinista, lo cierto es que existe una esfera de practicidad en torno a la alimentación en el ámbito de la vida cotidiana de los actores sociales que no podemos pasar por alto. Dicha practicidad es aquello que Geertz ha denominado como sentido común, y que radica en la sabiduría de los sujetos sobre la experiencia cotidiana (1994: 111). 
Esta practicidad o control para las mujeres de la familia Pérez Díaz, asentada en la zona conurbada de San Cristóbal de Las Casas, originarias de Huitepec de las Flores, el control de lo que se come significaría la posibilidad de guisar para sus hijos, pero como trabajan fuera de sus hogares pues no tienen tiempo para ello. No obstante, el sentido común les dicta no permitir a sus hijos comer frituras, no sólo por el costo de la compra sino, sobre todo, porque no tienen certeza de sus ingredientes y procesos de elaboración.

Los migrantes son en cierto modo agentes del cambio de dieta, sin embargo, las propias transformaciones tienen sus matices. Por ejemplo, esta familia de origen tsotsil asentada desde hace décadas en la ciudad compra en ocasiones comida de los puestos de venta en la calle y no de restaurantes porque en los primeros pueden observar cómo lo sirven, y la señora Clara Pérez arguyó que "cuando se comía más pobre estábamos más sanos y buenos [refiriéndose a lo considerado como "pobre" por provenir del campo]; y ahora que tenemos más dinero comemos diferentes cosas [que se compran], pero estamos enfermos [que es el costo por vivir en la ciudad]". ${ }^{2}$ De igual forma, otra mujer miembro de la familia, comentó que "por las tardes salen los vecinos que tienen paga [dinero] a tomarse una Coca afuera de su casa para que los demás vean que tienen dinero para comprar un refresco". Esta forma de demostrar que se tienen posibilidades económicas también se presenta cuando hay una negación a la posibilidad de producir sus propios alimentos e ingredientes. Otro caso es el que relató una vecina de la zona norte de la ciudad acerca de una mujer joven extranjera que llegó a su colonia y comenzó a hacer un huerto doméstico en su traspatio. Los vecinos - que en su mayoría eran migrantes tsotsiles y tseltales— la miraron con lástima pues "la pobrecita era tan pobre que no tenía para ir a comprar a las tiendas y tenía que sembrar en su casa". Argumentaron que "antes sembrábamos en la comunidad [de origen] pero que ahora que vivimos en la ciudad ya no lo acostumbramos porque sólo la gente pobre hace eso, los que no tienen qué comer". ${ }^{3}$

Siguiendo entonces el argumento de Geertz, el sentido común en tanto interpretación de las inmediateces de la experiencia está construido históricamente y, por tanto, está sujeto a interpretaciones y juicios también definidos históricamente (Geertz, 1994: 96). El control de lo que se come es contextual, de tal forma que la posibilidad de observar la elaboración de los alimentos, si no ya de tener certeza sobre la procedencia de los ingredientes, representa al menos una posibilidad para aceptar consumir algo o no. Evidentemente los individuos tienen agencia, por lo cual sería imposible generalizar los procesos y hábitos alimenticios en tanto que las respuestas de los sujetos, y la reconfiguración de lo alimentario hace posible una gran diversidad de cocinas: comidas, formas de nombrar y preparar alimentos, y también formas de apropiarse de tradiciones culinarias ajenas como ocurre con los kanjobales originarios de Guatemala, quienes aban-

\footnotetext{
2 Testimonio de la señora Clara Pérez, San Cristóbal de Las Casas, junio 2017.

3 Testimonio de vecina de la zona norte, San Cristóbal de Las Casas, junio 2017.
} 
donaron la preparación del borrego para adoptar el "mole" chiapaneco como una forma de identificarse con una suerte de cultura regional a partir de la obtención del estatus como asimilados. Esto nos habla de una adaptación de los migrantes a nuevos patrones alimentarios. Lo mismo aplica para la recepción y adaptación de muchos otros aspectos socioculturales que los migrantes integran a sus vidas como la música, las formas de organización social, los sistemas normativos, las técnicas agrícolas, etcétera.

Asimismo, el control como una noción que puede explicar aquello que les permite a estas sociedades saber la procedencia de lo que comen, necesariamente incluye aspectos mitológicos relacionados con el origen del maíz y el ciclo de lluvias y secas, y el vínculo de este calendario agrícola con el ciclo ceremonial. El control entonces tiene que ver con la agencia de las entidades sagradas, con las cuales se negocia porque tienen el poder de controlar calamidades, y también se caracterizan por poseer la facultad de proveer abundancia o precariedad en los cultivos. De igual manera, la tierra, para la vida de las familias indígenas, ha tenido un papel estructurante: es el espacio para el maíz, base de la alimentación. La tierra constituye el territorio propio y uno de los espacios donde el trabajo colectivo permite el flujo de las relaciones sociales. Los ciclos ceremoniales, la vida social y familiar han estado regidos por las actividades agrícolas, todos ellos han obedecido de una u otra forma a la particular relación con la tierra, lo cual se observa en los rituales de petición de lluvia que se llevan a cabo el 3 de mayo en prácticamente todas las regiones indígenas. El control tiene que ver con el conocimiento de los tiempos y de las fases de la luna que regula los periodos de siembra y cosecha.

Igualmente, el control implica la solvencia o bien la capacidad económica para ampliar el repertorio de comida y el acceso a distintos bienes alimentarios, por ejemplo, el creciente consumo de platos de "comida china" por parte de la población indígena en los contextos urbanos, tanto de migrantes asentados como de aquellos que por alguna razón visitan la ciudad de San Cristóbal de Las Casas. Nos referimos al acceso a pequeños restaurantes de cocina de origen chino donde tsotsiles de distintas localidades de Los Altos acuden a comprar verdura u otros productos que el lugar expende y se detienen como comensales en el bufete que ofrecen.

Los locatarios de origen cantonés y los dependientes de los establecimientos aseguran que en sus inicios la venta de comida china se concentraba en Tapachula, ciudad donde habían migrado grupos procedentes de Cantón que buscaron ofrecer alimentos aunque no eran cocineros en sus lugares de origen. Encontraron en la población tapachulteca un gusto por su cocina y decidieron agregar cantidades mayores de sal, grasa, azúcar y carne para adaptarse a los gustos locales. ${ }^{4}$ Sin embargo, los comensales no eran de origen indígena como lo son hoy, y eso trae a la luz otro aspecto de importancia para el control de lo que se

\footnotetext{
${ }^{4}$ Entrevista a descendiente de migrantes chinos en Tapachula, 2017.
} 
come: el gusto; el gusto como un dispositivo del control ante los alimentos que se evitan o rechazan por su sazón y porque marcan otras identidades.

El gusto puede generar una marca de otredad en condiciones de subordinación, es decir, el establecimiento de un gusto social que posiblemente comenzó por la imposición de algunos individuos que tuvieron posibilidades para acceder a otros alimentos además de los producidos o vendidos localmente. Ejemplo de ello son los comerciantes y distribuidores de productos alimenticios en los pueblos, tales como los expendios de pan industrializado, refrescos y frituras que se concentran en manos de las élites de poder local y regional.

Como se ha mencionado con anterioridad, evidentemente el gusto por ciertas formas de la comida y la alimentación en general se modifican con el tiempo y por ello son contextuales. De igual manera, las propias categorizaciones que los grupos e individuos confieren unos a otros en el campo de la comida establecen las formas de aceptación social, o bien asientan el estigma como un atributo desacreditador (Goffman, 2006: 13), bajo el cual se determinarán las formas de relación social, y por ende, la diferencia y la desigualdad. La relación entre ladinos (mestizos) e indígenas en tanto confrontación de alteridades se visualiza, por un lado, en las transformaciones del ambiente observadas en la diversidad de paisajes, y por otro, en la corporización de la diferencia y la desigualdad.

\section{Indígenas y ladinos: la corporización de la diferencia y las desigualdades}

Desde la perspectiva indígena, es en el campo de la alimentación donde es posible trazar la diferencia entre grupos indígenas. Pese a que la relación entre estos sectores es compleja, pues ambos son heterogéneos en su interior y en las maneras en que se relacionan entre sí, las preferencias por cierto tipo de comidas y la forma de alimentarse permite configurar los imaginarios de ambas alteridades en torno a los espacios que se ocupan y la conformación de los cuerpos, los humores, el balance entre lo frío y lo caliente, la salud-enfermedad y el tamaño y figura corporales. Lo anterior no obsta para determinar también la existencia de formas sociales y categorías linguísticas para distinguir a los grupos etarios de una familia con base en los alimentos que le son propios y cuya ingesta es determinante para reafirmar su pertenencia a un grupo específico. Durante la Colonia, las diferencias entre el trigo y el maíz terminaron por expresarse en las distinciones étnicas y sociales que separaban a los conquistados de los conquistadores. El trigo pasó a ser un objeto de consumo para la clase criolla y española, mientras que el maíz en forma de tortilla se restringió a los indígenas más pobres (Pilcher, 2001: 52); los indígenas se aferraron a su maíz y los españoles al trigo para hacer pan (García, 1995: 274). De igual forma, a diferencia de la dieta diaria indígena que no incluía productos lácteos, la ingesta de leche de vaca desde muy temprana edad ha sido un elemento alimenticio constitutivo de la formación de las familias mestizas de Chiapas, tal como lo indicó un miembro de la familia Samayoa de 
Lagartero, Tapachula: "Nosotros nos criamos con leche de vaca como era antes pues, y $[\ldots]$ nosotros hacíamos nuestros quesos". ${ }^{5}$

Al respecto, es pertinente mencionar que, a partir del levantamiento zapatista, la oferta de tipos de cocina mexicanas o extranjeras provocó cambios en los patrones alimentarios en ciudades chiapanecas. La población local se abrió a la cocina vegetariana de perfil global y también a las propuestas de slow food y lo orgánico por parte de distintos sectores de la población que han hecho de la alimentación el eje de una forma de vida. Hace un par de décadas, una de las vías para el fomento de la conversión religiosa al islam fue la comida, en particular la elaboración y comercialización del pan a través de panaderías de españoles musulmanes como Las Alpujarras establecida en San Cristóbal de Las Casas.

Cabe señalar que las preferencias por ciertos alimentos imponen formas de consumir o en general de cocinas vinculadas a grupos sociales caracterizados por diferentes "estilos de vida" (Goody, 2017: 141, 248), y en ocasiones las cocinas locales se convierten en sistemas gastronómicos más complejos como fue documentado por Jack Goody a partir de casos históricos. Para este antropólogo la naturaleza de una cuisine o cocina está relacionada con el sistema de producción y distribución de alimentos. Esto es, la disponibilidad de ciertos ingredientes y la integración de elementos de otras tradiciones culinarias a partir del comercio y grandes sistemas de producción agrícola. Algunos ejemplos de ello son la China imperial cuyas élites determinaron estilos de cocina y alimentos en general, al mismo tiempo que buscaron mantener cierta abundancia para la posibilidad de alimentar a la población de grandes ciudades (Goody, 2017: 132). La propia división de la labor culinaria por género ha definido históricamente las formas de alimentarse. Por igual, el contraste entre las prácticas alimentarias de los productores y cierto tipo de consumidores de grupos dominantes generó estructuras simbólicas que dieron significados diferentes a los alimentos de un grupo a otro (Goody, 2017: 275), como la construcción histórica de un estigma.

El imaginario acerca de la alimentación propia de las ciudades y la que se considera característica de un espacio rural refleja ambigüedades y ambivalencias. Por ejemplo, asociar lo urbano con mayores posibilidades para alimentarse, y por el contrario, para el caso de sociedades campesinas, la tendencia de una alimentación básica menos variada aunque no necesariamente de menor calidad. Entre los ejidos ch'oles enclavados en las montañas del norte, en Tila, se procura la reproducción de la milpa como sistema fundamental de subsistencia alimentaria y sustento de las distintas cosmovisiones. La milpa, al ser más que el maíz, provee de alimentos para los animales y de hierbas para el consumo cotidiano. Pero también existen creencias que trazan aspectos negativos de las prácticas alimentarias de la ciudad, como en Rayón, donde algunas mujeres han comentado que "a los niños les gusta [comer], comen puro caballo viejo que los hacen en máquinas...

\footnotetext{
${ }^{5}$ Testimonio registrado en la localidad de Lagartero, Tapachula, 2016.
} 
[en forma de] salchichas". ${ }^{6}$ La cercanía a las ciudades y el desarrollo urbano son considerados como nocivos en cuanto a que la gente modifica sus patrones de consumo y deja de buscar una alimentación diversificada porque sólo compra los productos: "[...] tenemos tantas cosas, pero como todos somos haragán no queremos investigar ahorita [acerca de cómo cocinar productos locales]". ${ }^{7}$

Así como se observan las redes de interacción social en los intercambios rituales y ceremoniales a través de la comida, es posible determinar el paisaje que se construye a partir de ésta, y que va de la mano con las necesidades en la producción y circulación. Cabe señalar que las poblaciones de las zonas indígenas están abiertas a la experimentación de nuevos cultivos, particularmente en aquellos destinados a la comercialización. Por ejemplo, en la década de 1980, en las tierras bajas del municipio de Tila, se transformó el paisaje como consecuencia de la caída del precio internacional del café. La crisis económica condujo a la tumba a los cafetos y su sustitución para la acelerada producción de ganado; dicho paisaje también se vio modificado por la renta de parcelas para la producción extensiva de maíz híbrido. De igual forma, algunas zonas de los municipios alteños se modificaron debido a los cultivos extensivos de legumbres monopolizados por familias chamulas para su comericalización en el mercado José Castillo Tielemans y la Central de Abastos en la ciudad de San Cristóbal de Las Casas.

Asimismo, podemos referir otros aspectos del paisaje en los ejidos de la selva en el municipio de Palenque, donde predominaban los pastizales para la cría del ganado. Durante mucho tiempo la ganadería convivió con la milpa pero ambas perdieron terreno ante la introducción de la agroindustria de la palma africana o aceitera (Oleasis oleifera). Pero tiempo después, debido a las experiencias negativas de los agricultores por las consecuencias de desgaste de los suelos después de su cultivo, se viró de nueva cuenta hacia la producción extensiva de árboles de hule, la cría de pollo de granja o la producción de yuca.

Años atrás, en la región del Soconusco, en el municipio de Motozintla, predominaban en el paisaje los cañaverales, pero ante su desaparición debida al huracán Stan en el 2005, los agricultores se inclinaron por la siembra de platanares, cebolla y repollo. Otra es la situación de las poblaciones mam que habitan en las zonas altas de localidades como El Porvenir, Malé, Canadá, Las Flores en el municipio de La Grandeza, cuya altitud y clima les ha permitido dedicarse a la plantación del cafeto.

\section{Estigma: los dominios de la comida, la diferencia y la salud-enfermedad}

De acuerdo con Goffman (2006: 12), existe una identidad social virtual (los supuestos que tenemos y desde los cuales partimos) y una identidad social real. Un

\footnotetext{
${ }^{6}$ Testimonio registrado en la localidad de Rayón, 2015.

${ }^{7}$ Testimonio registrado en Copainalá, junio 2017.
} 
atributo de menosprecio que una sociedad construya sobre la identidad virtual de otro grupo, la convierte en un estigma. Siguiendo al autor, en el discurso cotidiano se emplean designaciones específicamente referidas al estigma, tales como inválido, bastardo, ${ }^{8}$ y se podría agregar también: indio (Alonso, 2008: 298).

El estigma se construye con base en la diferencia, en la alteridad, así, la carga negativa de la identidad es colocada en los atributos de lo distinto por lo que existe en muchos casos una búsqueda por transformarse, por parecerse al otro cuando se está en condiciones de subordinación. Así, el grupo estigmatizado responde en su posición de inferioridad intentando "corregir" lo que considera el fundamento objetivo de su diferencia (Goffman, 2006: 19). Por ejemplo, la adopción zoque de ciertas esferas de la tradición cultural mestiza y tsotsil, como la preparación de la comida con aceite comercial, así como el uso de salsas y pastas industrializados para la elaboración de moles y guisos en casas y pequeños restaurantes (Alonso, 2008). Sin embargo, la estigmatización tiene sus matices y escalas frente a fenómenos que hemos registrado en esta investigación en torno a las prácticas alimentarias, pues los grupos sociales tienen agencia y pueden sostener su existencia sin colocar dichas prácticas en condiciones de inferioridad. En ocasiones, la diferencia se establece más como la experiencia de lo extraño. Una comida puede resultar tan extraña que los zoques de las estribaciones del volcán El Chichonal recurren a la frase "saber comer algo" cuando se enfrentan a lo desconocido o bien cuando ofrecen un guiso local a algún fuereño. Esta experiencia de lo extraño se puede establecer también en relación con la diferencia en la corporeidad cuando reconocen aspectos que se contemplan como significativos para distinguir un indígena de un mestizo, sea por la estatura, el color, el olor, pero sobre todo por la forma del cuerpo y la salud-enfermedad.

Así como los patrones y prácticas alimentarios forman parte y se concretan en el paisaje, como vimos con anterioridad, también forman parte de los esquemas identitarios formulados a partir de la comida y del control de lo que se ingiere configurando de cierto modo la corporalidad. Según Csordas, el cuerpo es concebido como un campo de elaboración discursiva y que trasciende el hecho de ser también materialidad y biología. El cuerpo, comprendido como entidad relacional, "es una cuestión de carne compartida, mutuamente implicada y nunca completamente anónima" (Csordas, 2013: 293), donde se localiza la experiencia del mundo. El cuerpo es un recurso de la existencia y, en consecuencia, trasciende a una entidad orgánica.

Al respecto, algunos agricultores ch'oles de Nueva Esperanza y del ejido de Tila hacen referencia al carácter que tienen como "gente natural" que los hace diferentes a los mestizos, en cuanto a que consumen lo que ellos cultivan de la "manera tradicional", sin fertilizantes y con el machete y el azadón; en la misma tónica, los campesinos zoques de Nuevo Carmen Tonapac insisten en la necesidad

\footnotetext{
${ }^{8} \mathrm{Goffman}$ reconoce varios tipos de estigma, uno de ellos radica en lo que toca a "estigmas tribales de la raza, la nación y la religión”, que son los que aquí nos ocupan (2006: 14-15).
} 
de controlar y cuidar sus parcelas trabajando con herramientas que consideran tradicionales (Figura 3). De tal suerte que comer sus maíces, sea en forma de tortilla o pozol, ${ }^{9}$ fortalece su cuerpo a diferencia de aquellos que consumen maíces híbridos. O bien como dice don Luviano, habitante mochó de la colonia El Mojón, en Motozintla: "la gente mestiza del centro come más carne de res, de puerco [...] están como los caballos que se encuentran en engorda, que están como inflados porque comen lo que le inyectan [hormonas de crecimiento] al ganado: son grandes y gordos, son pura inyección [los alimentos que comen están inyectados]". ${ }^{10}$ Esta forma de ver y entender el mundo marca el carácter diferenciador entre las formas que cobra lo alimentario en el mundo indígena y el mundo mestizo, así como entre el ámbito rural y el urbano, cuyas fronteras parecieran de pronto desdibujarse.

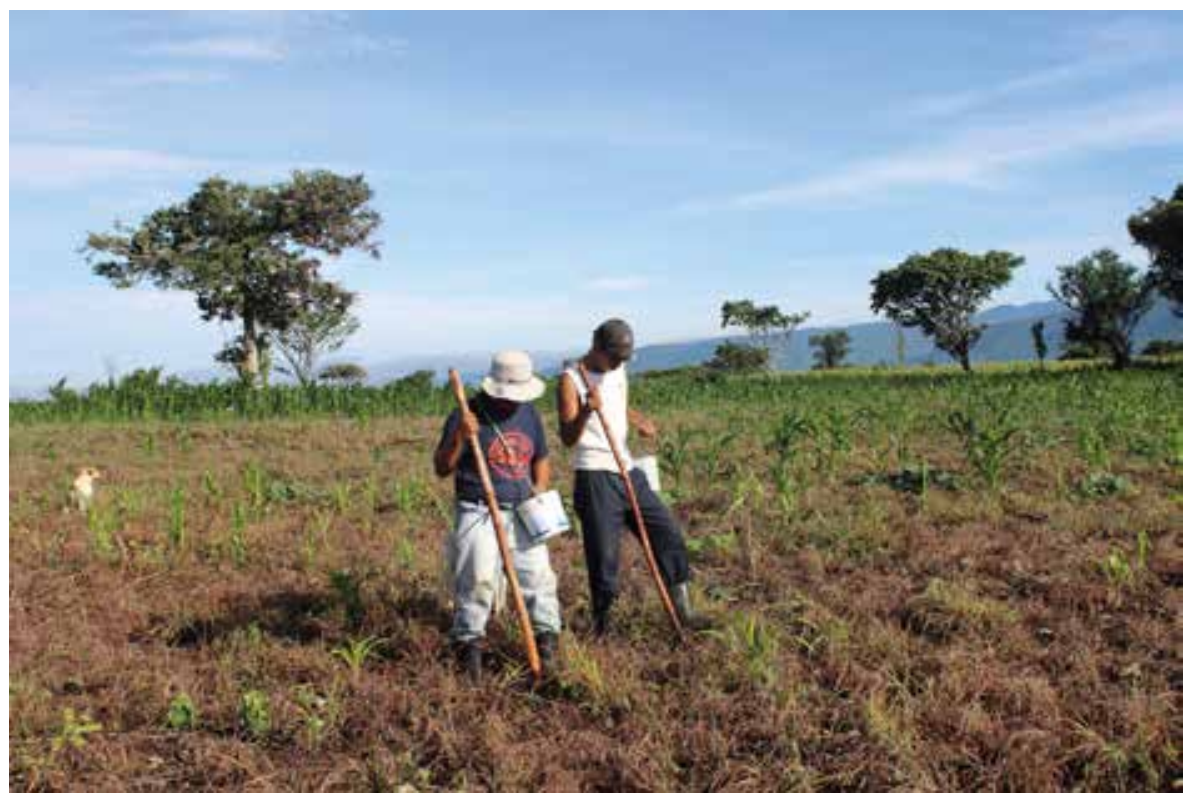

Figura 3. Campesinos zoques en Nuevo Carmen Tonapac, 2015 (Fotografía de Fermín Ledesma).

Asimismo, en los dominios del cuerpo, el fenómeno de salud-enfermedad nos coloca ante otra cara de lo alimentario en relación con el control de lo que se come y aquello que se rechaza. Debemos subrayar el papel destacado que ha ocupado la relación entre los alimentos y la salud-enfermedad; como indica Vargas (1989: 3), a nuestros días han llegado los conceptos de alimentos y enfermedades

\footnotetext{
${ }^{9}$ El pozol es una bebida fría de masa de maíz disuelta en agua.

${ }^{10}$ Entrevista con don Luviano, colonia El Mojón, Motozintla, octubre del 2016.
} 
frías, calientes, templadas, que tienen su origen en la época prehispánica y la inclusión de elementos durante la Colonia. De ahí que en la actualidad se considere el cambio en las prácticas alimentarias y en la enfermedad como un riesgo latente pues, como se ha mencionado, los alimentos están relacionados con el tipo de enfermedades que se pueden adquirir, por ejemplo, lo que se conoce entre los ch'oles como "la maldad" — asociada a los brujos- se adquiere por no tener control de lo que se come. Particularmente existe más riesgo cuando se está al frente de cargos políticos de representación colectiva por lo que se debe mantener cautela para aceptar una invitación a comer. Por igual, cuando una persona proporciona los alimentos durante una fiesta y éstos no fueron suficientes para todos los invitados, tanto el anfitrión como sus familiares enfermarán de "verguienza de pollo" o "cerdo". Para la curación se utiliza lembal (aguardiente) bebido y rociado para que el aroma del aguardiente ahuyente a los malos espíritus (Gutiérrez y Pacheco, 2013: 263-264).

Por su parte, para los mochó existe una estrecha relación entre la comida y la salud/enfermedad, pues más allá de las asociaciones a los malos espíritus, don Luviano, curandero de Motozintla planteó que afecciones como el alto índice de ácido úrico y colesterol se deben a los cambios en la alimentación. De manera que el rechazo a cierto tipo de comida se debe a que no se tiene control sobre su origen y las sustancias empleadas para su conservación, pero también ante los temores de que son los causantes de diversos males. Por su parte, el director del bachillerato de Palenque argumenta que los jóvenes enfermos, entre los que considera a los homosexuales — como si se tratara de un padecimiento-, son más visibles y numerosos en los últimos años en esa ciudad porque son resultado del consumo de alimentos de origen animal inyectados con hormonas para su rápido desarrollo. Esta permanente preocupación por las propiedades de los alimentos (Goody, 2017: 152), también conlleva ideas en torno al cáncer y a diversos problemas estomacales. Pero otro tipo de afecciones, como la diabetes, no se asocia a la herencia genética, a los hábitos alimentarios o al exceso del consumo de azúcar en los refrescos, sino que en las regiones de estudio se vincula con la enfermedad del susto.

En su texto Sweetness and Power, Mintz (1985) refiere el gusto humano por lo dulce, sin embargo, esta categoría de alimentos en la actualidad, al menos en los casos de la población indígena que nos ocupa, se centra en el excesivo consumo del azúcar —y en particular de Coca Cola_-; este hecho debe comprenderse en contextos específicos debido a la asignación de significados que individuos y grupos dan a los usos de lo dulce que se ha transformado con el tiempo. Asimismo, la combinación del azúcar con otros alimentos, léase café, chocolate, té, etcétera (Mintz, 1985: 6-11), resulta de gran relevancia para comprender los contextos en los cuales se consume. Sin caer en falsas generalizaciones sobre el consumo de Coca Cola entre la población indígena de Chiapas, resulta pertinente mencionar el uso medicinal del refresco, pues se utiliza como suero para la deshidratación y para proporcionar energía a los enfermos. Pero también grupos tsotsiles 
asocian al refresco con el pukuj o diablo, pues tienen la creencia de que está elaborado con sangre humana obtenida de algún hospital de San Cristóbal de Las Casas. ${ }^{11}$

Otro caso que evidencia la relevancia del control de la comida para las poblaciones indígenas es el de las kiu-syi o cocineras de Nuevo Carmen Tonapac, enclave zoque del municipio de Chiapa de Corzo. Al igual que los especialistas rituales zoques, estas "comideras" adquieren el don de cocinar a través del sueño (Alonso, 2013). La responsabilidad que implica su cargo se pone a prueba durante las fiestas cuando se les ha solicitado la preparación de platos ceremoniales, pues en caso de que alguna kiu-syi pierda el control debido a que no cumplió con las expectativas de los comensales, sea porque no sirvió abundante carne de puerco a los danzantes o tamboreros o porque la cantidad fue insuficiente, la cocinera podrá ser objeto de las prácticas de la brujería, y el "daño" adquirido se expresará en dolencias en el cuerpo, sobre todo en brazos y manos.

El padrino de la fiesta y la kiu-syi son responsables de definir a quién o a quiénes se les debe ofrecer las primeras viandas respetando la jerarquía de las autoridades tradicionales. Por ejemplo, los danzantes, tamboreros y kubguy jiara (padre del pueblo, autoridad tradicional) serán los primeros en recibir las raciones, las cuales deben estar cuidadosamente seleccionadas: se procurará no darles huesos sino abundante carne con caldo y acompañada de piezas consideradas "especiales, como el hígado del puerco", ${ }^{12}$ de lo contrario se entenderá que la kiu-syi no es apta para preparar la comida ni que el padrino es el adecuado para dar seguimiento a la celebración.

Ahora bien, el control de lo que se come está asociado con las características que posibilitan a las personas reproducirse como tales (Figura 4). Para muchas poblaciones indígenas comer tortillas elaboradas con los maíces nativos los hace fuertes y resistentes, características corporales que aseguran compartir con los pollos: los que son de rancho comen maíces nativos y por eso su carne es más dura, mientras que los pollos de granja se alimentan de maíces híbridos que debilitan su carne y huesos, justo como cuando los humanos consumen tortillas preparadas con Maseca. ${ }^{13}$ La población que migró hacia las ciudades asegura vivir bajo cierta incertidumbre sobre el control del cuerpo y la salud-enfermedad debido a su vulnerabilidad como habitantes de la ciudad; por ejemplo, para los tsotsiles asentados en San Cristóbal de Las Casas los traspatios no son funcionales debido a que los barrios donde habitan son abastecidos de agua cada cuatro días, mientras que en el paraje el manantial los proveía del líquido para beber, regar las hortalizas y mantener hidratados a los animales.

11 Testimonio registrado en San Cristóbal de Las Casas, junio 2016.

12 Testimonio registrado en Nuevo Carmen Tonapac, 2015.

${ }^{13}$ Maseca es la harina industrializada de maíz nixtamalizado, producida por la empresa del mismo nombre subsidiaria de Gruma, y que ha acaparado el mercado para la elaboración de masa para tortillas. 


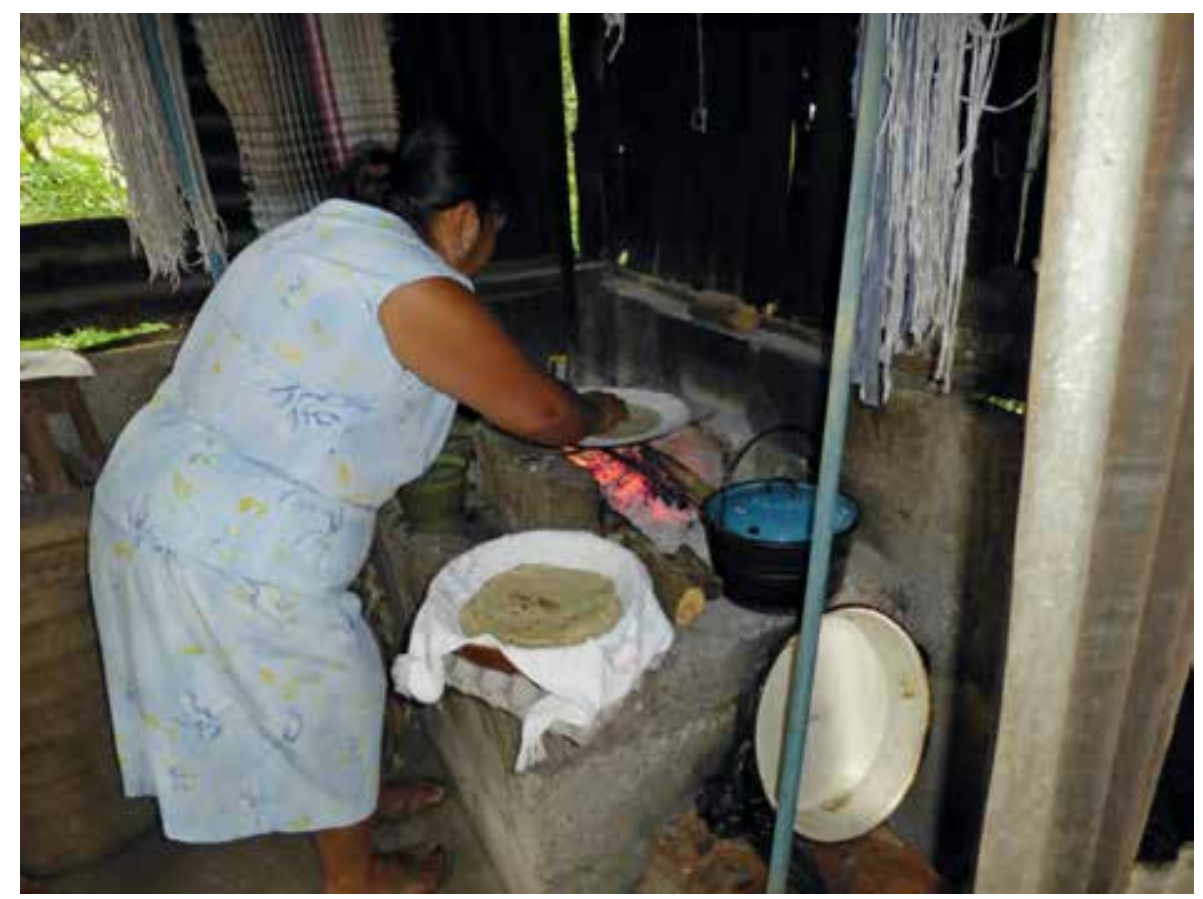

Figura 4. Preparación de tortillas en el fogón de la señora Gómez, Chapultenango, 2015 (Fotografía de Marina Alonso).

Como parte del control de lo que se come, las poblaciones locales o ciertos sectores ponen en marcha estrategias para la alimentación o subsistencia que se expresan en el rechazo de los alimentos que les proveen organismos gubernamentales. Así, las personas piensan que los alimentos son "buenos" o "malos" dependiendo del grado de injerencia que tenga el gobierno en su producción; si bien piensan que las zonas rurales son pobres porque están desatendidas por las autoridades en comparación con la ciudad, al mismo tiempo aseguran que la comida del campo es limpia y, en cambio, la de la urbe está sucia y contaminada, por lo que es "mala". En Jerusalén, un pequeño ejido de la selva, un anciano reveló que "comer en la ciudad es muy malo" porque todo está hecho con "químicos" mientras que en la comunidad todo es "natural"; otro poblador refirió que el gobierno dirigía avionetas a los campos de la selva para fumigar las plagas del maíz, pero en realidad "es para que no exista producción porque luego te van a mandar la comida". ${ }^{14}$

Es común que la población local indique los cambios de la alimentación por la forma de prepararlos y el uso de aceite para guisar. De hecho, el momento de ruptura para determinar cuándo hubo un cambio en los patrones de alimentación

\footnotetext{
14 Testimonio registrado en el ejido Jerusalén, 2016
} 
es la sustitución de la manteca de cerdo por el aceite y las formas de cocer los alimentos, la leña por la energía eléctrica y el uso de microondas, mismos que han sido promovidos por los gobiernos pues, "icómo se comía [antes]? al natural: no que ahora aceite, no que ahora: si no hay eso, [aceite], [dicen] que no sabe rico, que el frijol frito, con esa... esas cosas que nos han destruido tanto". ${ }^{15}$ En la zona mochó de la Sierra Madre la construcción en torno a lo que significa ser ladino (mestizo) se basa en la diferenciación de lo alimentario. En esta región los mochó advierten que los mestizos comen mucha carne y lácteos, y por ello están inflados y pálidos. Y es que entre los mochó como sucede también con otras poblaciones indígenas de la entidad como los ch'oles, la alteridad se muestra a través del cuerpo. Es decir, el cuerpo produce sentido (Sabido, 2012: 149). Por ejemplo, en otros casos hay elementos de la diferencia que se establecen a través del olor corporal y de los humores del cuerpo. El desagrado de las alteridades produce relaciones sociales asimétricas (Sabido, 2012: 21) y genera procesos de estigmatización: "los indios huelen a tortilla y a leña", dicen algunos mestizos ${ }^{16}$ de Copainalá, localidad de origen zoque de la depresión central.

De acuerdo con Csordas (2013: 294), la corporalidad implica tanto tensión como intención. Es decir, los cuerpos no son pasivos ni inertes, esto es, no están "simplemente allí", sino que tienen una agencia, un cierto tipo de elección, existencia y responsabilidad. En otros casos registrados la diferencia se observa más bien en las prácticas cotidianas en general como una extensión de lo corporal. Al respecto, podemos citar el pasaje donde Monaghan narra que durante una cacería a la cual asistió con sus amigos mixtecos, éstos derribaron una colmena para degustar las larvas de abejas, y ofrecieron lo que consideraban como un manjar al antropólogo quien no pudo rechazar la invitación. Tiempo después, éste invitó en "revancha" a sus amigos a comer a casa y les ofreció sopa de cebolla. Molesto, uno de ellos tiró el contenido del plato y otro explicó que las cebollas no se podían comer demasiado debido a su olor y porque "lo vuelven a uno estúpido". Monaghan y Just se preguntaron entonces en torno a la existencia de un mutuo disgusto por la comida de los otros y la distinción que existe entre lo que se podría considerar para unos como alimento y lo que no lo es (Monaghan y Just, 2000: 58-59).

Lo anterior no resulta sorpresivo pues existen innumerables ejemplos de las distinciones entre lo considerado comida, y que van más allá del valor alimenticio: "los insectos no sólo son comestibles, sino que resultan muy nutritivos, mientras que las cebollas contienen grandes cantidades de vitaminas", continúan los autores (Monaghan y Just, 2000: 59). Aquí el punto es que ciertas categorizaciones de los estadounidenses generalizarían a los insectos como "bichos no comestibles" y la cebolla es considerada por los mixtecos como un condimento, es decir que comer es parte de un complejo sistema de ideas, normas, valores,

\footnotetext{
15 Testimonio registrado en Copainalá, julio de 2017.

16 Testimonio de la familia Cruz, Copainalá, junio de 2018.
} 
comportamientos, etcétera (Monaghan y Just, 2000: 60). Podría pensarse que la elección de lo que se come tendría que ver con lo que está disponible y que es comestible, pero no todo este universo es elegido para alimentarse. Los hábitos de comer de los diferentes sectores de la sociedad agrupados por edad, género, estatus, entre otros, pasan por las relaciones de poder, y el control de lo que se come atraviesa la organización social porque, por ejemplo, el parentesco define en cierta forma los modos en que se adquieren, preparan y consumen los alimentos (Mintz, 1985: 3, 5). Esto tiene que ver con un aspecto central que es la forma en que se come, es decir, la manera en que los grupos se reúnen para alimentarse.

Así, el poder estructural establece los marcos que definen las formas de producir la comida, prepararla y comerla. Así, el poder modifica los hábitos de consumo, perpetúa formas de comer y otorga nuevos significados (Mintz, 2003: 52). El comer alimentos de la ciudad o guisar con ingredientes utilizados por los mestizos les brinda prestigio social. De igual manera en que se traza la diferencia entre indígenas y mestizos en el campo de la comida, también se marca entre los distintos miembros de los grupos domésticos y sectores sociales al interior de las propias localidades indígenas, en particular, de frente a lo que se configura como distinto, ajeno, extraño, fuereño. La comida se ha utilizado para legitimar a los grupos de poder y el control de lo que se come, sosteniendo las asimetrías. Lo mismo sucede con los platos rituales; las comidas sacrificiales constituyen la circulación de alimentos entre desiguales; la demostración de la riqueza también se da en este ámbito. De igual forma, en tanto que el control de lo que se come se relaciona con las interacciones, la existencia de nuevas denominaciones religiosas en Los Altos, en particular en Chamula y Tenejapa, ha sido uno de los factores de transformación en cuanto a los hábitos alimenticios, y ha fomentado el estigma con respecto a las comidas rituales tradicionales al subrayar rasgos que se ven como negativos, tales como el gasto ceremonial que asocian al atraso, al despilfarro y la embriaguez.

Otro aspecto recurrente en las explicaciones locales acerca del control de los alimentos es la forma en que se preparan por parte de los propios sujetos y los utensilios con que se cocina. Esto tiene que ver con lo que Ayora considera como las producciones tecnocientíficas en la cocina. El autor advierte que las producciones tecnocientíficas de cada momento histórico, su aplicación y las preferencias de unos utensilios por encima de otros para cocinar ciertos tipos de comida no se reducen a un manejo utilitario - que de por sí se desfasa en el tiempo- sino que comprenden dimensiones afectivas, construcciones identitarias, relaciones translocales (Ayora, Vargas y Fernández, 2016).

Lo anterior se relaciona con la preocupación local por el gasto que se tiene que erogar para la compra de alimentos, desde los productos que una familia tiene por básicos, hasta enseres domésticos para cocinar y combustibles (leña y carbón, o gas en su caso). Algunas mujeres indígenas que han migrado con sus familias a las ciudades consideran que deben modificar ciertos patrones de ali- 
mentación porque no les rinde el día lo suficiente para cocinar, y algunos grupos se han convertido en compradores de comida rápida; de hecho, según locatarios de restaurantes, los habitantes de Chamula que acuden a San Cristóbal de Las Casas por distintas razones, como el bajo precio y la accesibilidad, son potenciales consumidores de pizzas y de diversos tipos de platos de ágil preparación.

\section{Poder y procesos alimentarios}

Como hemos indicado, en nuestra labor etnográfica hemos vislumbrado diversas problemáticas relacionadas con la alimentación y las estructuras locales de poder que, si bien son resultado de impactos globales, constituyen también respuestas locales de los sujetos y de sus agentividades en permanente tensión. En este apartado abordamos algunos aspectos de los programas gubernamentales en materia de alimentación y salud que son factores externos de peso e inciden en los patrones de producción, distribución y consumo de comida, es decir, influyen en el control de lo alimentario.

En 2012 inició una campaña de alimentación a través de varios programas gubernamentales con ayuda de las grandes agroindustrias productoras de alimentos del país. En su parte operativa, los programas conllevaron un condicionamiento partidista que incidió en la distribución de alimentos y materias primas, lo cual a la vez impactó en los hábitos alimentarios. Hace casi una década habíamos constatado los efectos alimentarios por parte del programa "Oportunidades" en el municipio de Copainalá. Los cambios en los hábitos alimenticios fueron notorios y favorecían el rendimiento escolar, pues las madres de familia afirmaban que los niños bebían leche y desayunaban antes de ir a la escuela. De igual forma, estos alimentos se complementaban con los desayunos escolares proporcionados en la escuela primaria y para el caso de los jóvenes de secundaria y preparatoria la opción de los padres era darles dinero para la compra de sus alimentos en la escuela aunque no hubiera garantía del tipo de productos que consumieran. Durante 2017 y 2018, las madres de familia adscritas a programas de alimentación en San Cristóbal de Las Casas recibieron instrucción bimensual por parte de nutriólogas para brindar una alimentación supuestamente equilibrada a sus hijos.

Sin embargo, tanto "Canasta alimentaria de corazón" como "Cruzada nacional contra el hambre" diseñados en el sexenio 2012-2018 por el gobierno estatal y federal, respectivamente, se orientaron a llevar alimentos en términos de cantidad y no de calidad a las zonas marginadas, a lo cual se sumó el hecho de que grupos de poder se disputaran el control de la operación de dichos programas. Para comprender esto en los casos que nos ocupan, determinamos dos escalas del poder.

La primera radicaba en las alianzas que establecieron los gobiernos con las empresas agroindustriales como estrategia para satisfacer la demanda de alimentos de la población rural e indígena y como una política orientada a impulsar a 
las microempresas del estado de Chiapas, a partir del cual se definió qué comer y quién lo debía comer, con lo cual se desplazaron las formas locales de alimentarse.

La segunda escala de las relaciones de poder y control fue la que observamos dentro de las comunidades durante la administración y distribución de los alimentos, una vez que los programas gubernamentales llegaron a los lugares previstos. En muchos de estos casos, los objetivos iniciales de los programas públicos fueron transformados por acuerdos locales, de tal suerte que los grupos de poder local crearon normas de regulación para controlar y excluir a las minorías opositoras al imponer criterios en los modos de distribuir y preparar la comida. Así es como la Secretaría de Desarrollo Social envió "enlatados" — nombre con que los receptores de los programas en Ocosingo distinguen los abarrotes, los paquetes de huevo, carne y leche deshidratados para su conservación que proporcionaba el gobierno- a los comedores comunitarios de Frontera Corozal en Ocosingo para que las mujeres ch'oles administraran los alimentos entre la población. Por su parte, en el ejido Jerusalén en Las Margaritas, el propio partido gobernante definía la distribución de las canastas alimentarias durante el tiempo en que se aplicaron los programas.

Ante ello, se generaron prácticas de resistencia como las de los ejidos del municipio de Ocosingo, en la zona selvática, en donde se rechazó la leche Diconsa, con el argumento de que no formaba parte de la dieta básica alimentaria ${ }^{17}$ de la mayor parte de la población indígena de la región. Asimismo, se arguyó que se trataba de "alimento de la ciudad" o bien que "hacía mal a los niños", lo cual es importante si consideramos que las poblaciones indígenas no han sido simples receptoras de las políticas públicas sino co-productoras de las mismas a partir de un juego de imposiciones y negociaciones (Alonso et al., 2013). Al respecto tenemos el caso del comedor comunitario ch'ol de Frontera Corozal adscrito al programa "Cruzada Nacional contra el hambre", el cual fue administrado por madres solteras. Siguiendo el objetivo del programa, las personas asimilaron "nuevos alimentos" en pos de mejorar los patrones de nutrición. Adicionalmente, las mujeres lograron que los comensales más asiduos — niños y ancianos - tuvieran acceso a los alimentos diarios a muy bajo costo, al tiempo que articularon una amplia red de intercambios regionales modificando las reglas de operación del programa que indicaban circunscribirse exclusivamente al desarrollo local.

La desconfianza que generó entre las personas el hecho de no tener control sobre el proceso de producción de la comida "enlatada" provocó que grupos tsotsiles insertaran estos artículos en circuitos comerciales paralelos y los revendieran a bajos precios a un tipo de consumidor urbano específico. Se trataba de mestizos de clase media o pobres, y de jóvenes mestizos y extranjeros, que buscaban adquirir alimentos económicos en los mercados del centro y la

\footnotetext{
${ }^{17}$ Probablemente se rechazaba la leche por el malestar que les causaba debido a la ausencia de la enzima que descompone la lactosa.
} 
periferia de la ciudad de San Cristóbal. Este fenómeno ilustra la relevancia del control de la comida para las poblaciones indígenas, así como las nuevas formas de mercar bienes, pero en los mismos espacios. Otro ejemplo lo encontramos en la localidad de Lagartero, municipio de Tapachula, donde las familias aseguran que generalmente se dirigen a los mercados para adquirir jabón, azúcar y aceite, pero nunca para comprar comida porque los alimentos que preferieren son los producidos y preparados en el seno doméstico; otro tipo de artículos como ropa o utensilios diversos pueden obtenerlos en las ferias de las fiestas.

Finalmente, nos referiremos a otro caso de gran complejidad e interés en torno al poder y los procesos alimentarios: el $p^{18}{ }^{18}$ y los refrescos o "bebidas carbonatadas y azucaradas en general" (Page, 2013: 119). El monopolio del aguardiente o pox fue promovido entre las comunidades de Los Altos por parte de los habitantes de San Cristóbal de Las Casas en la década de 1930 como forma de control político y económico de la zona, al tiempo en que fueron prohibidos y perseguidos los trapiches caseros (Fuente, 2009). Décadas después el ingenio de Huixtán se consolidó como una de las industrias del aguardiente que inundó el mercado en las zonas indígenas (Eber, 2008), en particular las ch'oles del norte, que hoy en día se conoce como "el huixtán" por la producción del pox; una de las causas de este crecimiento expansivo ha sido el bajo valor con el que se puede adquirir.

Existe una vasta producción académica con diversas perspectivas que han abordado el tema del consumo del pox en comunidades indígenas, por ejemplo, las investigaciones en antropología médica de Page (2013), Reyes (2009) y Polakoff y Vargas (2002), o bien acerca de las relaciones sociales en Chamula (Bunzel, 1991). Pero el trabajo del antropólogo mexicano Julio de la Fuente develó que el funcionamiento del monopolio del pox involucraba la red de relaciones entre los denominados "ladinos" y los funcionarios del gobierno estatal chiapaneco en la década de 1950 (Fuente, 2009: 141-177), lo cual desencadenó "la guerra del pox" (Lewis, 2004: 129-130). En esta línea de análisis también se encuentra el trabajo de Porras, quien apunta que la producción y comercio del pox estuvo vinculado al enriquecimiento de las familias mestizas que lo introdujeron en Los Altos (Porras et al., 2015: 81).

Por su parte, Eber enfatizó el rol contradictorio del pox entre los habitantes del pueblo tsotsil de Chenalhó porque, por un lado, era utilizado en prácticas curativas y, por el otro, provocaba graves problemas de violencia y salud en poblaciones empobrecidas y marginadas, en particular en las mujeres. Eber también resaltó la reflexión de los zapatistas que prohibieron el consumo del aguardiente en los municipios autónomos (Eber, 2008: 165-183).

Si bien la producción y consumo del pox y la chicha ${ }^{19}$ ha sido de relevancia para las localidades indígenas, el consumo de las bebidas carbonatadas comer-

\footnotetext{
${ }^{18}$ El pox es una bebida derivada de la caña de azúcar, de consumo ritual entre el sector católico tradicionalista de los pueblos tseltales y tsotsiles de los Altos de Chiapas.

${ }^{19}$ Bebida fermentada elaborada con panela, producto derivado de la caña.
} 
ciales implica también prestigio y posiciones diferenciadas en la estratificación social según una marca comercial u otra. El uso de Coca Cola y Pepsi en Los Altos ha sido también ampliamente documentado antropológicamente y tratado por igual por periodistas y miembros de organizaciones no gubernamentales ante el arraigo de dichas bebidas (Figura 4).

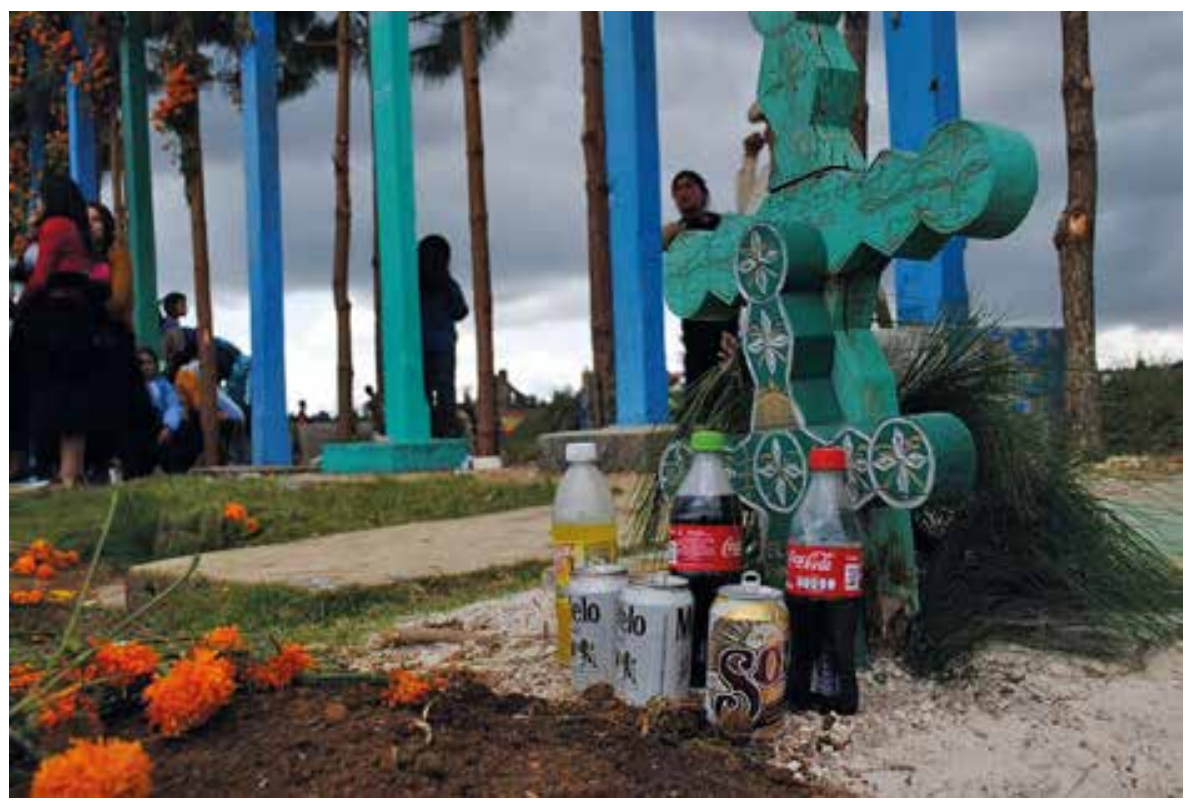

Figura 4. Ofrenda de bebidas en día de muertos. Romerillo, Chamula, 2015 (Fotografía de Rosalba Tadeo).

El tema del refresco de cola es de primordial importancia ya que es considerado alimento debido a la energía proporcionada por los endulzantes que contiene, pero sobre todo porque se le supone un don, un bien de intercambio que se utiliza para dirimir conflictos, negociar, y en su caso, para la reconciliación. En otras zonas indígenas de Chiapas, por ejemplo, la población zoque prefería beber infusiones frías hechas con la hoja de limón o naranjo, además de consumir café caliente o frío como agua de tiempo, costumbre que perdura en la actualidad. Sin embargo, a las visitas se les suele invitar refrescos de cola como un gesto de bienvenida.

Por su parte, es conocido que las élites políticas de Zinacantán y de Chamula utilizan Pepsi Cola y Coca Cola, respectivamente, como emblemas políticos de su rivalidad histórica. Aunque existen otras marcas más baratas y que tienen mayor presencia en otras regiones de Chiapas, ambos refrescos se han relacionado con las identidades políticas alteñas. Asimismo, las empresas han negociado con los líderes de los partidos políticos el control de la distribución de la bebida, pues 
la gente indica que "ningún candidato [a algún puesto de autoridad local] va a llegar [a ganar] sin refresco". Así, la política comercial se ha reflejado en la intensa campaña para acercase a la población; por ejemplo, en años anteriores sobre la carretera San Cristóbal-Tenejapa podía verse un letrero espectacular con un hombre vestido con traje tradicional (chamarro negro de lana) tomando Coca Cola, con una frase en tseltal aludiendo a lo bueno que es beber dicho refresco. Actualmente, aún pueden leerse frases en tsotsil que dicen "sa'o li k'usi leke" ["busca lo bueno"] en algunas de las tiendas de Zinacantán.

Según Mintz (1985: 185-186), el capitalismo industrial expandió el mercado del azúcar y de alimentos que inicialmente habían sido de prestigio para las clases altas y se insertó en la dieta de los obreros y las clases bajas como un alimento fácil de combinar y conseguir. Es pertinente entonces resaltar las concesiones de la distribución del refresco en diferentes grupos de poder y el hecho de que se haya instalado la planta de extracción de agua en Huitepec (Page, 2013: 122). En su estudio en torno a tsotsiles y tseltales diabéticos, Page señala que existen diferentes factores asociados a la importancia que ha adquirido el consumo del refresco en localidades cercanas a la carretera de los municipios de Tenejapa, Chamula y San Cristóbal. Al respecto, coincidimos con el autor con respecto a la vulnerabilidad de la población de Los Altos ante las estrategias de mercado de la industria refresquera que alentó el prestigio social, en particular en Chamula, por ofrecer Coca Cola, aspectos que se han sumado a la incidencia de grupos cristianos por la satanización del pox como bebida ritual (Page, 2013: 120-124).

Así, el control de la venta del refresco ejercido por los presidentes municipales condujo a la localidad de Mitzitón a un fuerte conflicto que tuvo como una de sus consecuencias el desplazamiento de 60 familias hacia Teopisca. Dichas familias no sólo eran obligadas a consumir Coca Cola durante fiestas y asambleas locales, sino que debían comprar rejillas de refresco en una determinada tienda. En otras zonas indígenas de Chiapas tenemos comportamientos similares de consumo de refrescos de cola; por ejemplo, de acuerdo con las autoridades municipales de Copainalá y la observación de los patrones de consumo, en los hogares más pobres de este municipio de origen zoque se bebe al menos un litro de Coca Cola cada tercer día.

De igual forma, por prescripción de su religión, los adventistas del Séptimo Día de Zacalapa y la cabecera municipal de Copainalá y Tecpatán no beben café ni alcohol además de que no consumen varios alimentos habituales para el resto de la población local y regional, como los caracoles de río. Sin embargo, es común que estos grupos beban Coca Cola, buscando que ésta sea envasada en botella de vidrio. Si bien, como se ha mencionado antes, el gusto por lo dulce representa una razón de la importancia del refresco en la dieta indígena, es un hecho que el azúcar y otras sustancias endulzantes proveen de calorías, por lo cual se considera un alimento caliente y energizante. En muchos casos, la gente comentó que el refresco les ayuda a tener fuerza y olvidar el hambre mientras trabajan e incluso, en ocasiones, prefieren ingerir Coca Cola sobre el pozol pues 
la sensación de llenura es inmediata. Asimismo, los recipientes plásticos del refresco son reutilizados para conservar y transportar otras bebidas: agua, pozol u aguardiente; también muchas personas cortan la base de las botellas para usarla como utensilio.

\section{Consideraciones finales}

Nuestras etnografías se han abocado a documentar las prácticas alimentarias como fuerzas impulsoras de la sociabilidad (Haller, 2011: 107). La alimentación se presenta como el rasgo fundamental que articula los diferentes ámbitos de las sociedades indígenas, desde la reproducción de cosmovisiones ligadas a la agricultura, la salud y la enfermedad, cuyos rituales de curación están ligados a los alimentos. De igual forma, la alimentación sostiene las relaciones sociales intraétnicas particularmente en las fiestas o en las percepciones de lo que significa comer de manera adecuada mediante el control.

A partir de lo que se come, los individuos se construyen a sí mismos y a los otros. En este artículo hemos abordado algunas concepciones con respecto a la elaboración y consumo de los alimentos en relación con la significación de la comida y su asociación con la estratificación social, estigmatización, conflictos, conformación y confrontación de identidades (Mintz, 2003: 36), en un contexto más complejo característico de la condición global actual.

Los procesos alimentarios, hábitos y prácticas de consumo constituyen un eje problemático que permite dimensionar y comprender la diversidad cultural y las desigualdades, por lo que la categoría de "control" en cuanto punto de partida nos permitió engarzar los datos etnográficos obtenidos entre la población de localidades de origen tsotsil, tseltal, zoque y ch'ol. Así, en la reflexión de nuestra experiencia de campo figuró el "control" como una categoría conceptual que posibilitaba dar sentido a la información etnográfica desde la perspectiva de los sujetos de investigación y sus procesos de agencia. A través de la noción de control se establecieron diálogos transversales sobre diferentes contextos y pueblos. Finalmente, el control nos permitió comprender el imaginario colectivo de sociedades que han puesto el acento en esquemas regulados por ideas y creencias como motor de sus prácticas en permanente ajuste al complejo contexto que configura el Chiapas indígena actual con sus múltiples y heterogéneos escenarios.

\section{Agradecimientos}

Agradecemos por su colaboración en la realización del trabajo de campo a Tania Rueda, Delmar Méndez, Alain Giraud y Ana Laura Pacheco del Programa Nacional de las Regiones Indígenas, Instituto Nacional de Antropología e Historia. Asimismo, agradecemos a los dictaminadores cuyas sugerencias enriquecieron este texto. 


\section{Bibliografía}

Alonso, Marina

2008 "Los indios de los indios: los chimas de los tecos. Notas en torno a la construcción histórica de una identidad estigmatizada”, Los zoques de Oaxaca. Un viaje por los Chimalapas, pp. 287-316, Leopoldo Trejo y Marina Alonso (coords.). México: Instituto Nacional de Antropología e Historia.

2013 "Todo tiene su misterio. La experiencia onírica en la iniciación y la práctica de los músicos zoques de Chiapas", Los sueños y los días. Chamanismo y nahualismo en el México actual, pp. 201-212, Miguel Bartolomé y Alicia Barabas (coords.). México: Instituto Nacional de Antropología e Historia.

Alonso, Marina, Javier Gutiérrez, Rodrigo Megchún y Víctor Acevedo

2013 "Habitar el entorno: experiencias socioambientales en cuatro regiones indígenas de Chiapas", Resultados de investigación de la línea: Patrimonio Biocultural de México del Programa Nacional de Etnografía de las Regiones Indígenas de México, Eckart Boege (coord.). México: Instituto Nacional de Antropología e Historia.

Alonso, Marina, Javier Gutiérrez, Mauricio Sánchez y Fermín Ledesma

2015 "Procesos socioambientales y las diferentes formas de ser 'joven indígena' en Chiapas", Resultados de investigación de la línea: Pueblos indígenas y procesos socioambientales del Programa Nacional de Etnografía de las Regiones Indígenas de México, Aída Castilleja y Javier Gutiérrez (coords.). México: Instituto Nacional de Antropología e Historia.

Arnáiz, Mabel Gracia (coord.)

2008 Somos lo que comemos. Estudios de alimentación y cultura en España. Barcelona: Ariel Antropología.

Ayora, Steffan Igor

2002 Globalización, conocimiento y poder. Médicos locales y sus luchas por el reconocimiento en Chiapas. México: Universidad Autónoma de Yucatán, Plaza y Valdés.

Ayora Díaz, Steffan Igor, Gabriela Vargas y Francisco Fernández

2016 Cocina, música y comunicación. Tecnologías y estética en el Yucatán contemporáneo. Mérida: Universidad Autónoma de Yucatán.

Bunzel, Ruth

1991 "El rol del alcoholismo en dos culturas centroamericanas", Antropología del alcoholismo en México, los límites culturales de la economía política 1930-1979, pp. 201-246, Eduardo Menéndez (coord.). México: Centro de Investigaciones y Estudios Superiores en Antropología Social.

Carrasco Henríquez, Noelia

2007 "Desarrollo de la antropología de la alimentación en América Latina: hacia el estudio de los problemas alimentarios contemporáneos", Estudios Sociales, 15 (30): 80-101. 
Csordas, Thomas

2013 "Fenomenología cultural corporeidade: agencia, diferencia sexual e doença", Educação, 36 (3): 292-305.

Delgado, Manuel

1999 El animal público. Hacia una antropología de los espacios urbanos. Barcelona: Anagrama.

Eber, Christine

2008 Agua de Esperanza, agua de pesar. Mujeres y alcohol en un municipio maya de los Altos de Chiapas. Massachusetts: Plumsock Mesoamerican Studies, Centro de Investigaciones Regionales de Mesoamérica (Serie Monográfica, 17).

Fuente, Julio de la

2009 Monopolio de aguardiente y alcoholismo en los Altos de Chiapas. Un estudio "incómodo" de Julio de la Fuente (1954-1955). México: Comisión Nacional para el Desarrollo de los Pueblos Indígenas (Pioneros del indigenismo en México, 1).

García Acosta, Virginia

1995 "El pan de maíz y el pan de trigo: una lucha por el dominio del panorama alimentario urbano colonial", Conquista y comida. Consecuencias del encuentro de dos mundos, pp. 265-282, Janet Long (coord.). México: Universidad Nacional Autónoma de México.

Geertz, Clifford

1994 Conocimiento local. Ensayos sobre la interpretación de las culturas. España: Paidós.

Goffman, Erving

2006 Estigma. La identidad deteriorada. Buenos Aires: Amorrortu editores.

Goody, Jack

2017 Cocina, cuisine y clase. Estudio de sociología comparada. Barcelona: Gedisa.

Gutiérrez, Javier y Ana Laura Pacheco

2013 "La maldad y los malos espíritus están en el aire y en las personas. Curanderos y nahuales entre los ch'oles de Tila, Chiapas”, Los sueños y los días. Chamanismo y nahualismo en el México actual, pp. 251-274, Miguel Bartolomé y Alicia Barabas (coords.). México: Instituto Nacional de Antropología e Historia.

Haller, Dieter

2011 Akal-Atlas de etnología. España: Akal.

Harris, Marvin

2011 Bueno para comer. Madrid: Alianza Editorial.

Lewis, Stephen E.

2004 "La guerra del posh, 1951-1954: un conflicto decisivo entre el Instituto Na- 
cional Indigenista, el monopolio del alcohol y el gobierno del Estado de Chiapas", Mesoamérica, 46: 111-134.

Mauss, Marcel

1979 Sociología y antropología. Madrid: Tecnos.

McMichael, Philip

2015 Regímenes alimentarios y cuestiones agrarias. México: Universidad Autónoma de Zacatecas, Red Internacional de Migración y Desarrollo, Miguel Ángel Porrúa.

Mintz, Sidney

1985 Sweetness and Power. The Place of Sugar in Modern History. Nueva York: Penguin Books.

2003 Sabor a comida, sabor a libertad: incursiones en la comida, la cultura y el pasado. México: Centro de Investigaciones y Estudios Superiores en Antropología Social.

Monaghan, John y Peter Just

2000 Una brevísima introducción a la antropología social y cultural. México: Océano.

Page, Tomás

2013 "Refresco y diabetes entre los mayas de Tenejapa, San Cristóbal de Las Casas y Chamula, Chiapas”, LiminaR. Estudios Sociales y Humanísticos, XI (1): 118-133.

Pilcher, Jeffrey M.

2001 iQue vivan los tamales! La comida y la construcción de la identidad mexicana. México: Centro de Investigaciones y Estudios Superiores en Antropología Social, Ediciones de la Reyna Roja, Consejo Nacional para la Cultura y las Artes.

Polakoff, Karen y Luis Alberto Vargas

2002 "Del trago a la tragedia. Consecuencias del consumo de alcohol en San Juan Chamula, Chiapas", Alcohol y comunidades indígenas. Ritual y patología. Cuadernos Seminarios Fundación de Investigaciones Sociales A.C., 1 (12): 43-52.

Porras Gómez, Iván, Francisco Alonso y Rafael Alonso

2015 “ ¿ 'El costumbre' de los dioses o la imposición de los infieles? Cosmovisión y comercialización del posh en los Altos de Chiapas”, En torno a las bebidas alcohólicas mexicanas. Poder, prácticas culturales y configuraciones regionales, pp. 77-87, José de Jesús Hernández y Miguel Ángel Iwadare (coords.). México: Universidad de Guadalajara.

Reyes Gómez, Laureano

2009 "Ingesta de alcohol entre indígenas de Chiapas. Estudio de cuatro casos", LiminaR. Estudios sociales y humanísticos, VII (1): 176-189. 
Reygadas, Luis

2004 "Las redes de la desigualdad. Un enfoque multidimensional", Política y Cultura, 22: 7-25.

Sabido, Olga

2012 El cuerpo como recurso de sentido en la construcción del extraño. Una perspectiva sociológica. México: Universidad Autónoma Metropolitana, Unidad Azcapotzalco.

Turner, Victor W.

1988 El proceso ritual. Estructura y antiestructura. España: Taurus.

Vargas, Luis Alberto

1989 Raíces culturales del México actual. México: Universidad Nacional Autónoma de México, Instituto de Investigaciones Antropológicas.

Marina Alonso Bolaños. Mexicana. Doctora en Historia por El Colegio de México. Es investigadora del Instituto Nacional de Antropología e Historia y sus principales líneas académicas se centran en la antropología e historia de poblaciones zoques; coordina el equipo de Chiapas del Programa Nacional de Investigación “Etnografía de las regiones indígenas de México”. Entre sus publicaciones recientes se encuentran Creando mundos, entrelazando realidades: cosmovisiones y mitologías en el México Indígena (co-coordinadora), "Somos otros, pero recordamos de dónde venimos como zoques" y "Applied Ethnomusicology: A Critical History of Indigenous Music Studies in Mexico”.

cenizadevolcan@gmail.com

Javier Gutiérrez Sánchez. Mexicano. Doctor en Antropología por la Universidad Nacional Autónoma de México. Su línea de investigación se centra en los procesos socioambientales y participa en el Programa Nacional de Investigación "Etnografía de las regiones indígenas de México" del Instituto Nacional de Antropología e Historia. Entre sus últimas publicaciones se encuentran "Ser jóvenes en distintos contextos choles del norte de Chiapas", "Cosmovisiones e identidades" y "De hombres, naturaleza y entidades sagradas. Visiones del mundo indígena en Chiapas”, los dos últimos en coautoría.

javiergutie64@hotmail.com

Fermín Ledesma Domínguez. Mexicano. Maestro en Desarrollo Rural por la Universidad Autónoma de Chapingo, actualmente cursa el doctorado en Desarrollo 
Rural en la Universidad Autónoma Metropolitana, Unidad Xochimilco. Sus principales líneas de investigación son el territorio y el extractivismo en poblaciones indígenas; desarrolla el proyecto "El pueblo zoque en movimiento. La defensa del territorio frente a la ronda petrolera en el norte de Chiapas". Entre sus publicaciones recientes se encuentran "La rebelión delahuertista en Pichucalco, Chiapas (1923-1924). Reconstrucción de hechos" y Las tierras zoques de Chiapas. Territorio, extractivismo y resistencia indígena.

fer.ledesma.d@gmail.com

Rosalba Tadeo Castro. Maestra en Antropología Social por la Universidad Nacional Autónoma de México. Participa en el Programa Nacional de Investigación "Etnografía de las regiones indígenas de México" del Instituto Nacional de Antropología e Historia. Sus investigaciones se centran en la región tseltal de los Altos de Chiapas y su proyecto actual se titula "El carnaval del pueblo tseltal de Tenejapa". Entre sus publicaciones recientes se encuentran "Breve diagnóstico sociocultural e histórico de las comunidades incluidas en el estudio de la cuenca del río Almandros, Huitiupán, Chiapas-Tacotalpa, Tabasco" y "Memoria y tradición en San Juan Ixtayopan", esta última como autora única.

rostadeo@gmail.com 